\title{
THE EFFECT OF HALF-SHAFT TORSION DYNAMICS ON THE PERFORMANCE OF A TRACTION CONTROL SYSTEM FOR ELECTRIC VEHICLES
}

F. Bottiglione

Politecnico di Bari, DIASS (Visiting Researcher at the University of Surrey for the project described in this article)

Via A. De Gasperi s/n Viale Japigia 182

74100 Taranto

Italy
A. Sorniotti, L. Shead
University of Surrey
Guildford, Surrey GU2 7XH
United Kingdom

\begin{abstract}
This article deals with the dynamic properties of individual wheel electric powertrains for fully electric vehicles, characterised by an in-board location of the motor and transmission, connected to the wheel through half-shafts. Such a layout is applicable to
\end{abstract}


vehicles characterised by larger power and torque requirements where the adoption of in-wheel electric powertrains is not feasible due to packaging constraints. However, the dynamic performance of in-board electric powertrains, especially if adopted for antilock braking or traction control, can be affected by the torsional dynamics of the halfshafts. This article presents the dynamic analysis of in-board electric powertrains in both the time and frequency domains. A feedback control system, incorporating state estimation through an extended Kalman filter, is implemented in order to compensate the effect of half-shaft dynamics. The effectiveness of the new controller is demonstrated through the analysis of the performance improvement of a traction control system.

\section{Keywords}

In-board electric powertrain; half-shaft torsional compliance; traction control.

\section{Introduction}

The traditional layout of electric vehicle powertrains consists of a central motor, a single-speed or multiple-speed transmission, a differential and half-shafts [1-4]. However, the future of electro-mobility is likely to be based on the adoption of individually controlled powertrains for each wheel [5]. From the viewpoint of vehicle

dynamics, this solution provides significant advantages, due to the possibility of 
implementing direct yaw moment control for the enhancement of vehicle response in steady-state and transient conditions [6-8], and for the actuation of anti-lock brake system (ABS) and traction control (TC) functions. This is achievable through the precise control of the electric powertrain torque at the wheel. However, current regenerative braking systems for electric powertrains usually leave the modulation of the braking torques to the friction brakes, and reduce the regenerative action during ABS cycling [9-11], whilst traction control systems based on the actuation of internal combustion engines are characterised by a relatively low bandwidth. The low reaction time and high bandwidth of electric motor drives potentially allow the development of ABS controllers based on direct slip control [12-17] instead of the conventional hybrid controllers based on the combination of wheel acceleration control and wheel slip control [18].

Individual in-wheel electric powertrains provide an additional benefit from the viewpoint of the design of the overall vehicle chassis, by permitting an increase of the available volume in the area between the wheels. However, current motor technology is limited in terms of power and torque density, which makes in-wheel powertrains, with their motor drive unit incorporated into the vehicle unsprung mass, a viable solution only for small and medium size cars, with relatively low performance. Despite recent studies [19-20] which suggest a past overestimation of the importance of this factor, inwheel electric powertrains are associated with an undesired increase of vehicle 
unsprung mass, with the subsequent ride comfort and vehicle dynamics implications (for rough road conditions). Moreover, the adoption of an in-wheel powertrain on the wheels of a steering axle increases the turning radius of the vehicle, due to the related packaging issues.

As a consequence, a possible solution for the implementation of individual electric powertrains, without being subject to the limitations of the in-wheel layout, is the implementation of in-board electric powertrains. These are characterised by a motor drive and a transmission connected to the vehicle chassis through a powertrain mounting system (possibly including bushings with non-linear elastic and damping properties), and by a half-shaft with constant velocity joints for driving the wheel. However, the main disadvantage of the in-board electric powertrain arises from the torsional dynamics of the half-shaft and the subsequent first torsional mode of the powertrain. The torsional dynamics of the electric drivetrain is due to the fact that the half-shaft can be considered as the combination of a torsion spring and damper (with very low damping ratio) in parallel, connecting the equivalent mass moment of inertia of the drivetrain to the inertia of the wheel. Moreover, the torsional dynamics of the system are significantly affected by the slip ratio dynamics of the tyres, due to the combination of tyre steady-state non-linear characteristics and relaxation length. In a first approximation, tyres can be represented as non-linear dampers within the system. Also the dynamics of the electric powertrain mounting system, especially if the 
drivetrain includes bushings, is relevant to vehicle drivability, because of the forces transmitted to the vehicle chassis by the powertrain mounting system. All these phenomena could interfere with vehicle drivability, by affecting jerk dynamics, as is well known for internal combustion engine driven vehicles [21], usually characterised by a first natural frequency of the powertrain between 4 and $7 \mathrm{~Hz}$. The torsional mode of the powertrain could also reduce the effectiveness of ABS and TC actuation. However, the literature about electric vehicle control has not investigated this aspect yet.

This article provides a comprehensive analysis of the dynamics of in-board electric powertrains, in both the frequency and time domains. A potential limitation in the actuation of effective ABS and TC systems is demonstrated. A feedback controller, based on an extended Kalman filter [22] for the estimation of the half-shaft torque, is implemented for the compensation of half-shaft torsional dynamics during $\mathrm{ABS}$ and $\mathrm{TC}$ intervention, which is a novel control approach for this important application. A similar algorithm has been implemented in [23] for the compensation of the effect of the transmission plays on electric vehicle drivability.

\section{The Simulation Model}

This section describes the basic principles of the implemented non-linear model of the longitudinal dynamics of a case study front-wheel-drive vehicle with individually 
controlled powertrains. A non-linear powertrain model is developed (and subsequently used as a simulator), from which a linearised vehicle model is derived for controller design purposes. The model presented in this section includes a significant number of simplifications, and has been selected as the simplest non-linear model capable of reproducing the dynamics of interest for the specific application [21].

Figure 1 is the schematic of an individual wheel powertrain, characterised by a threestage single-speed transmission with a layshaft layout. The equivalent mechanical model implemented in this article consists of three degrees of freedom: the vehicle, the wheel and the powertrain. The half-shaft is modelled as a torsion spring and damper with two mass moments of inertia at its ends. The damping coefficient of the half-shaft is low due to the very small internal damping of the material (steel). The connection between the wheel and the equivalent inertia of the vehicle is represented by the tyre. The angular speeds of the wheel and the equivalent inertia of the vehicle differ because of the slip ratio. 


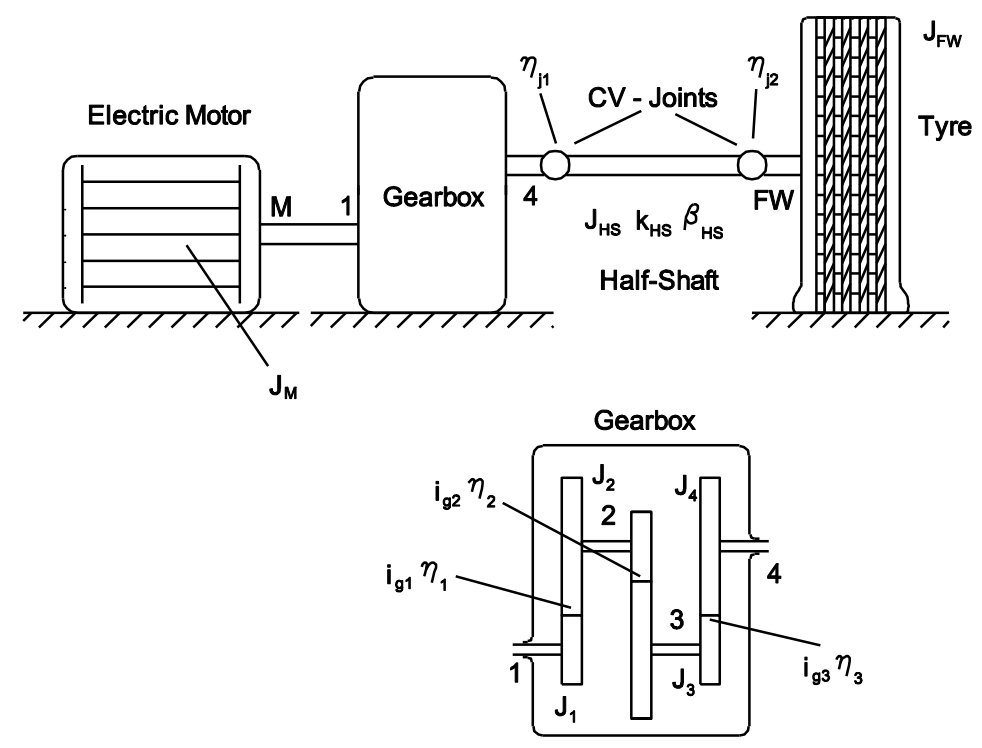

Figure 1 -Schematic of the individual in-board electric powertrain with a zoomed view of the three-stage single-speed transmission

The electric motor reaction time and slew rate are included in the simulation model. The specific motor drive unit of this vehicle application is of a switched reluctance topology, characterised by a particularly low value of mass moment of inertia. A small time constant $\tau_{M}$ takes into account the effect of the electric dynamics of the motor (due to its equivalent circuit parameters):

$\tau_{M} \dot{T}_{M}+T_{M}=T_{M, r e f}$

Equation (2.2) models the overall powertrain dynamics from the motor shaft to the transmission output shaft. A look-up-table based model is adopted for the estimation of the windage losses $T_{\text {windage }}$, which are functions of the rotor angular velocity: 


$$
\begin{aligned}
& T_{M}-T_{\text {windage }}-\frac{i_{g 1} i_{g 2} i_{g 3}}{\eta_{1} \eta_{2} \eta_{3} \eta_{j 1}} T_{H S}=\left[\left(J_{M}+J_{1}\right)+\frac{i_{g 1}^{2}}{\eta_{1}} J_{2}+\frac{\left(i_{g 1} i_{g 2}\right)^{2}}{\eta_{1} \eta_{2}} J_{3}+\right. \\
& \left.+\frac{\left(i_{g 1} i_{g 2} i_{g 3}\right)^{2}}{\eta_{1} \eta_{2} \eta_{3}}\left(J_{4}+\frac{1}{2} \frac{J_{H S}}{\eta_{j 1}}\right)\right] \ddot{\theta}_{M}
\end{aligned}
$$

where half-shaft torque $T_{H S}$ is given by:

$$
T_{H S}=\beta_{H S}\left(i_{g 1} i_{g 2} i_{g 3} \dot{\theta}_{M}-\dot{\theta}_{F W}\right)+k_{H S}\left(i_{g 1} i_{g 2} i_{g 3} \theta_{M}-\theta_{F W}\right)
$$

Transmission efficiency is modelled through a look-up-table-based model, as a function of the input torque, speed and operating temperature. Starting from $T_{H S}$, equation (2.4) calculates the net torque $T_{F W}$ transmitted by the half-shaft to the wheel:

$$
T_{H S}-\frac{T_{F W}}{\eta_{j 2}}=\frac{J_{H S}}{2} \ddot{\theta}_{F W}
$$

Equation (2.5) is the rotational equilibrium of the driven wheel:

$$
T_{F W}-T_{d, F W}-f_{r, F} F_{z, F W} R_{W}=J_{F W} \ddot{\theta}_{F W}
$$

Tyre rolling resistance coefficient $f_{r}$ is modelled as a parabolic function of the tangential speed of the wheel. Tyre longitudinal force $T_{d, F W} / R_{W}$ is modelled using the Pacejka magic formula [24], including a relaxation length model for the evaluation of the transient effects, according to equation (2.6):

$$
\frac{L_{t y r e}}{\dot{\theta}_{F W} R_{W}} \dot{T}_{d, F W}+T_{d, F W}=T_{F W, \text { Pacejka }}
$$

$L_{t y r e}$ is a function of wheel speed, tyre vertical load and slip ratio. 
Vehicle longitudinal dynamics are modelled through an equivalent moment of inertia, which is subject to equivalent torques due to the aerodynamic drag and the driven and undriven (the rear ones for the specific case study vehicle of this article) wheels. Equation (2.7) describes the dynamics of the equivalent inertia of the vehicle:

$$
2 T_{d, F W}-2 f_{r, R} F_{z, R W} R_{W}-\frac{1}{2} \rho C_{d} S R_{W}^{3} \dot{\theta}_{V}^{2}=\left(2 J_{R W}+m R_{W}^{2}\right) \ddot{\theta}_{V}
$$

Given the focus of the activity, the wheel vertical load transfers due to the longitudinal acceleration and deceleration levels have been computed considering neither the effect of suspension stiffness and damping, nor tyre vertical dynamics. For example, the vertical load on each front wheel is equal to:

$$
\begin{aligned}
& F_{z, F W}=m g \frac{b-u_{R W}}{2\left(L+u_{F W}-u_{R W}\right)}+\frac{1}{4\left(L+u_{F W}-u_{R W}\right)} \rho S R_{W}^{2}\left[-C_{d} h_{C G}+C_{m} L+\right. \\
& \left.-C_{l}\left(b-u_{R W}\right)\right] \dot{\theta}_{V}^{2}-m \frac{h_{C G}}{2\left(L+u_{F W}-u_{R W}\right)} R_{W} \ddot{\theta}_{V}
\end{aligned}
$$

A similar equation is adopted for the computation of the vertical load on the rear axle. The most relevant vehicle data are included in Table B.1 of Appendix B.

Linearization permits the analysis of the frequency response of the system and control system design. The model described by equations (2.1)-(2.8) has been subject to linearization around an operating condition, defined by a value of vehicle velocity and slip ratio. In the linear model, the tyre is considered as an equivalent torsion damper between the wheel and vehicle inertia, where the equivalent damping coefficient is 
obtained through the linearization of the Pacejka magic formula around the selected operating point. The main non-linearities of the system are due to the tyre force characteristics. In particular, the absolute value of tyre longitudinal slip stiffness is positive and progressively decreasing from the condition of zero slip until the peak value of longitudinal force, at which it assumes a null value. When the longitudinal slip stiffness of the tyre is null, the individual powertrain dynamics are completely decoupled from the dynamics of the equivalent inertia of the vehicle. This offers the theoretical justification of the simplification carried out by most authors (for example, [12]) in the derivation of the dynamic equation of the slip ratio within the implementation of model-based ABS. Wheel dynamics are much more pronounced and at higher frequency values than vehicle longitudinal dynamics for conditions of slip ratios around the value generating the peak longitudinal tyre force. Beyond the peak longitudinal force, tyre longitudinal slip stiffness is negative. The linearised model has been implemented in a state-space formulation:

$\left\{\begin{array}{l}\dot{X}=A X+B U \\ Y=C X+D U\end{array}\right.$

The detailed mathematical formulation of the elements of the $X$ and $U$ vectors and the $A$ and $B$ matrices defined in equation (2.9) is included in Appendix A, with some marginal additional simplifications (e.g. the windage losses are neglected). Additionally, it is possible to predict that most in-board implementations of electric powertrains will be 
usually characterised by a lower length of the half-shafts (in comparison with internal combustion engine driven powertrains), due to the width of the system formed by the two electric motor units per each axle.

Assuming some particular vehicle parameters (Appendix B), the frequency response of the model has been analysed for a number of different linearization points, given the absence of any literature about the frequency response of such a powertrain layout.

Figure 2 contains the Bode plots of the adimensionalized half-shaft torque response to an input motor torque, for different values of slip ratio (linearization point), and two values of half-shaft length (i.e. half-shaft torsion stiffness), at a vehicle velocity of 50 $\mathrm{kph}$, in conditions of high friction coefficient $(\mu=1)$ between the tyre and the road surface. $i_{g}{ }^{*}$ is the overall single-speed transmission ratio $\left(i_{g}{ }^{*}=i_{g 1} i_{g 2} i_{g 3}\right)$. At low values of slip ratio (graphs at null slip ratio in the figure), the frequency response is characterised by two peaks, at the natural frequencies of the system. The first one is visible in the diagrams, and is located between 80 and $90 \mathrm{rad} / \mathrm{s}$ (about 13 and $14 \mathrm{~Hz}$ ), whilst the second peak is not visible, as it is located beyond the frequency limits of the plot. When the value of slip ratio at the linearization point is increased to 0.05 , the low frequency peak in the half-shaft torque response is subject to an amplitude reduction. Moreover, the frequency of the second resonance peak gets lower, and the two peaks become closer. This is the range of slip ratios usually relevant for vehicle drivability. Finally, for values of slip ratio close to the one corresponding to the peak longitudinal tyre force, 
the system experiences a significant resonance peak between 100 and $200 \mathrm{rad} / \mathrm{s}$ (about 16 and $32 \mathrm{~Hz}$ ). The frequency range of ABS modulation in common systems based on the hydraulic actuation of the friction brakes is between 4 and $7 \mathrm{~Hz}$. According to [25], the adoption of in-wheel motors can increase the ABS modulation frequency up to 9-10 Hz. This is the range of interest of this simulation model. Beyond these limits, there could be modal interactions with the longitudinal motion of the wheel relative to the chassis, due to suspension compliance, usually in the region of 40-100 $\mathrm{Hz}$ [26].
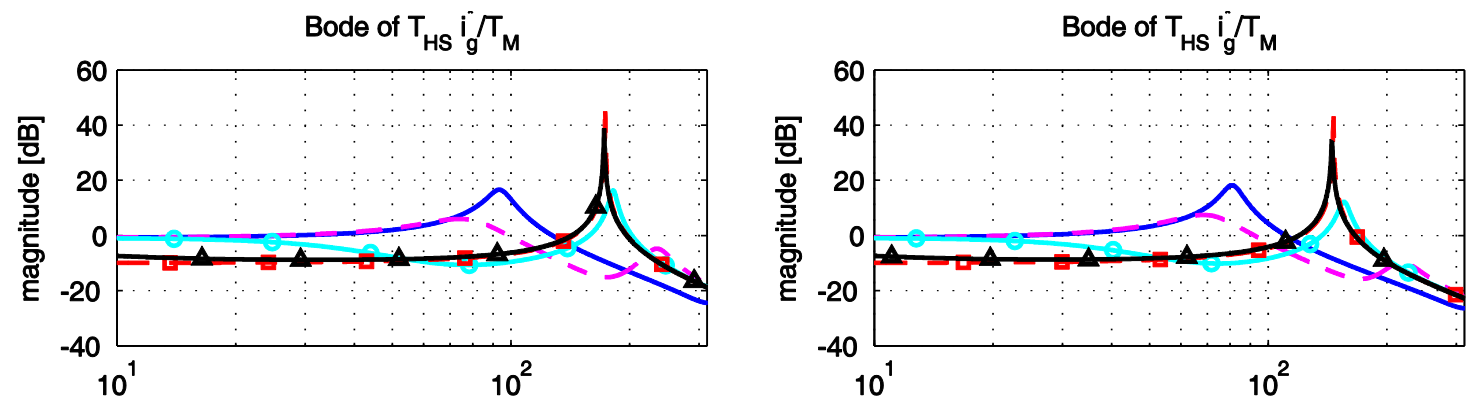

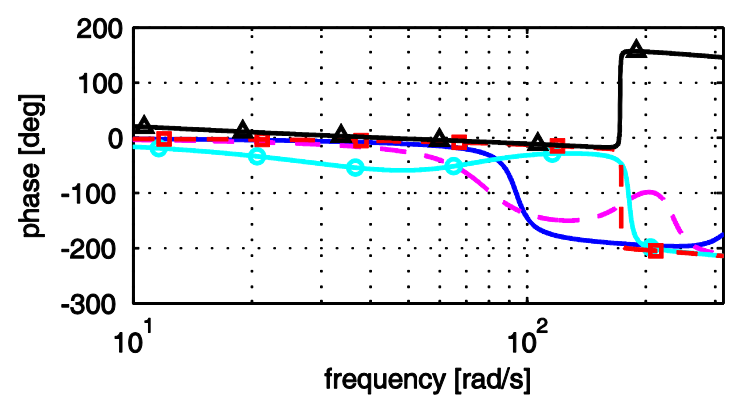

(a)

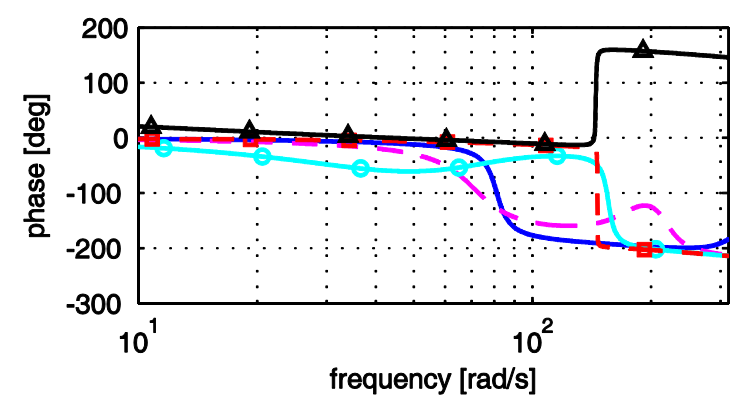

(b)

Figure 2 - Bode plot (magnitude and phase) of the adimensionalized half-shaft torque for an input torque request, at different values of tyre longitudinal slip ratio (continuous line) 0.0 , (dashed line) 0.05 , (o) $0.1,(\square) 0.138$ (peak), ( $\Delta) 0.15$. Vehicle speed is $50 \mathrm{kph}$. 
Two half-shaft lengths are shown: (a) $l_{H S}=506 \mathrm{~mm}$, (b) $l_{H S}=360 \mathrm{~mm}$

Figure 3 plots the sensitivity of the frequency response of the same electric powertrain to different values of the tyre-road friction coefficient, for a relatively low slip ratio $(\sigma=$ 0.05, Figure 3(a)), relevant to vehicle drivability, and a slip ratio close to the one corresponding to the peak value of tyre longitudinal force $\left(\sigma=\sigma_{P E A K}-0.01\right.$, Figure 3(b)). The frequency response of the system is strongly dependent on $\mu$, with the only exception being represented by the case of system linearization at exactly $\sigma_{P E A K}$, where all the Bode plots (for whatever $\mu$ ) are coincident. In fact, in that condition wheel dynamics are decoupled from vehicle dynamics, and so the tyre longitudinal slip stiffness is equal to zero. In the analysis of this preliminary research activity, the variation of the shape of the tyre force characteristic as a function of $\mu$ has been neglected (all the characteristics have been scaled down according to the assigned friction coefficient) and the existence of the peak of tyre longitudinal force has been considered also in conditions of very low friction. Future analysis will have to investigate the frequency response of the system in case of low friction surface with snow, which gives rise to a monotonically increasing tyre force characteristic as a function of the slip ratio.

In conclusion, the case study individual wheel powertrain is characterised by a higher value of the first natural frequency than the powertrain of an internal combustion engine 
driven vehicle, which results in an improvement of vehicle drivability. However, the open-loop dynamic response of the powertrain, due to the torsional dynamics of the half-shafts, is not satisfactory for ABS and TC based on direct slip control. For example, [12] mentions a bandwidth of $72 \mathrm{rad} / \mathrm{s}$ (about $11.5 \mathrm{~Hz}$ ) for the electromechanical friction brake callipers adopted in that specific vehicle application.

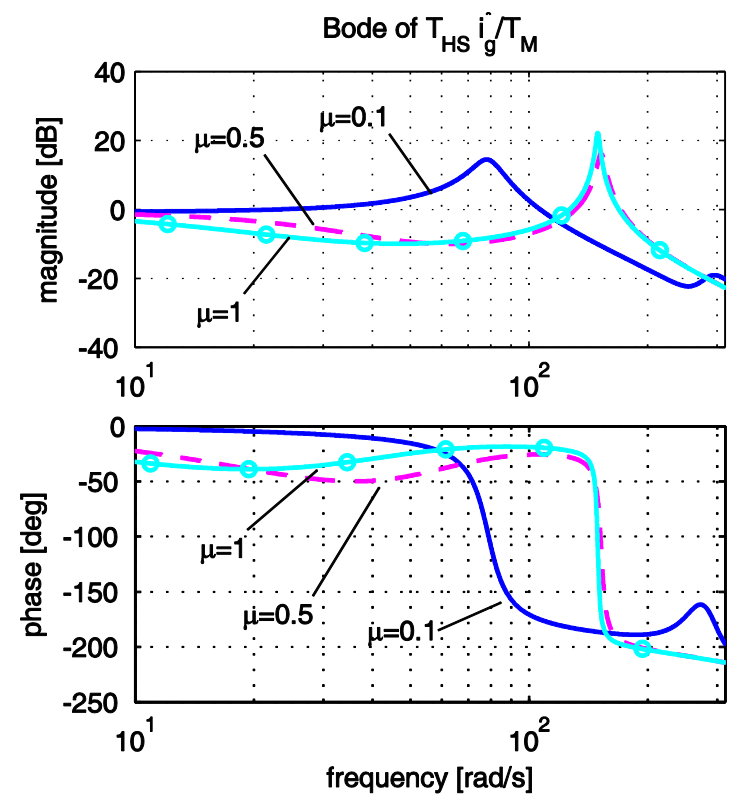

(a)
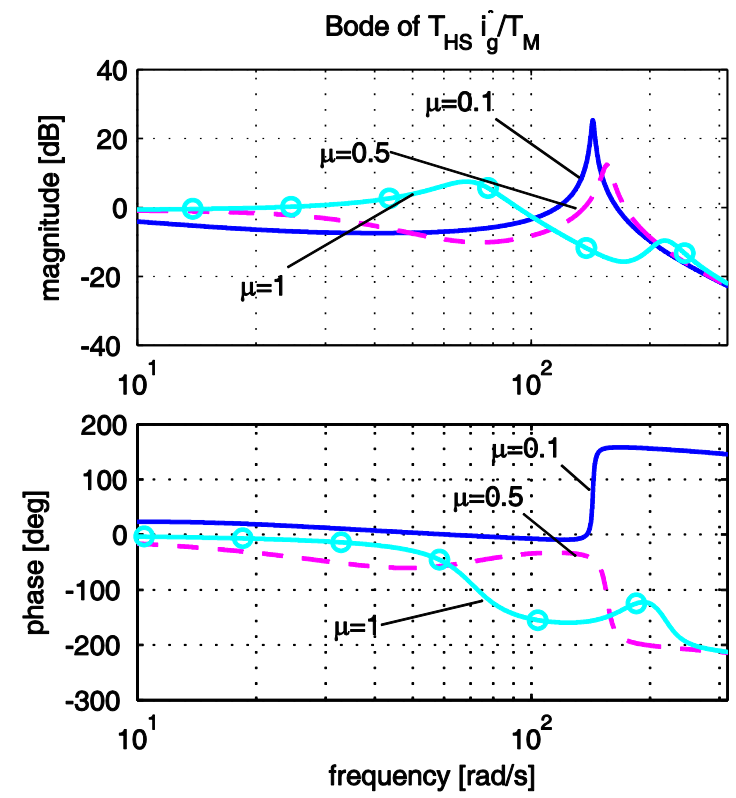

(b)

Figure 3 - Bode plot (magnitude and phase) of the adimensionalized half-shaft torque for an input torque request, at different values of tyre-road friction coefficient $\mu$ and with a longitudinal slip ratio $\sigma$ given by: (a) $\sigma=0.05$, (b) $\sigma=\sigma_{P E A K}-0.01$. Vehicle speed is $50 \mathrm{kph} . l_{H S}=506 \mathrm{~mm}$

\section{Control System Design in the Frequency Domain}


Figure 4 is the linearized block diagram of a TC based on slip ratio feedback control without any compensation of half-shaft torque dynamics, similar to the system presented in [27]. The estimation of the slip ratio implies the availability of precise information of vehicle longitudinal velocity, which can be easily derived, for the case of a two-wheel-drive vehicle, from the wheel speed sensors of the undriven wheels, which would be adopted in any case for the purpose of anti-lock braking control. This method for the estimation of vehicle speed is reasonably reliable also in case of cornering conditions. The main non-linearities of the control system are represented by the switch for the activation and deactivation conditions based on two different slip ratio thresholds, and by the fact that during TC activation the algorithm selects the lower between the driver torque demand and the output torque from the traction control system.

In the frequency domain, for a vehicle with a traction control system based on direct slip control implemented through a Proportional Integral Derivative (PID) controller, tyre slip ratio $\bar{\sigma}(s)$ is given by:

$\bar{\sigma}(s)=\frac{\left[\bar{\sigma}_{r e f}(s) K_{P I D, T C}(s)+\bar{T}_{M, r e f}(s)\right] G_{P L A N T}(s)}{1+K_{P I D, T C}(s) G_{P L A N T}(s)}$

The slip ratio is due to the combination of the reference torque contribution $\bar{T}_{M, r e f}(s)$ imposed by the driver and the torque correction calculated by the traction controller. For a first approximation design of the tracking performance of the traction controller, it is 
possible to consider the closed-loop transfer function of the control system, defined by the loop gain transfer function $K_{P I D, T C}(s) G_{P L A N T}(s)$ :

$$
G_{C L, T C, \text { conventional }}(s)=\frac{\bar{\sigma}}{\bar{\sigma}_{\text {ref }}}(s)=\frac{K_{P I D, T C}(s) G_{P L A N T}(s)}{1+K_{P I D, T C}(s) G_{P L A N T}(s)}
$$

In equation (3.1) the term $\bar{T}_{M, r e f}(s)$ can be ignored, as it can be considered a disturbance during a manoeuvre with TC intervention. For a second approximation design of the controller, the analysis of the robustness of the control system against the variation of driver torque demand during TC interventions should be carried out (not attempted in this paper).

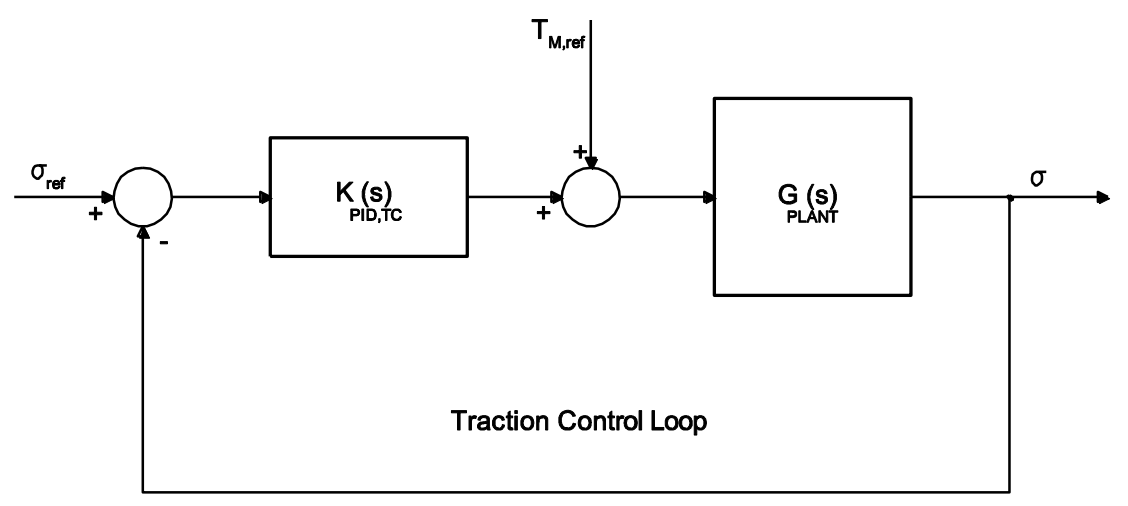

Figure 4 - Block diagram of a conventional TC based on direct slip control

ABS and TC based on direct slip control both need the precise actuation of the wheel braking and traction torques. These are characterised by significant dynamics (already outlined in section 2) if the reference motor torque for achieving a target wheel torque is 
purely calculated by the ABS or TC as the desired wheel torque multiplied by the transmission gear ratio ( $<1$ according to the conventions adopted in the article).

The idea of this research is the implementation of an inner control loop for the feedback compensation of the torque oscillations at the wheels (Figure 5). The feedforward component of the reference torque at the half-shaft is computed as the reference electric motor torque $\bar{T}_{M, \text { ref }}^{*}$, depending on driver input and the traction control, divided by $i_{g}{ }^{*}$.

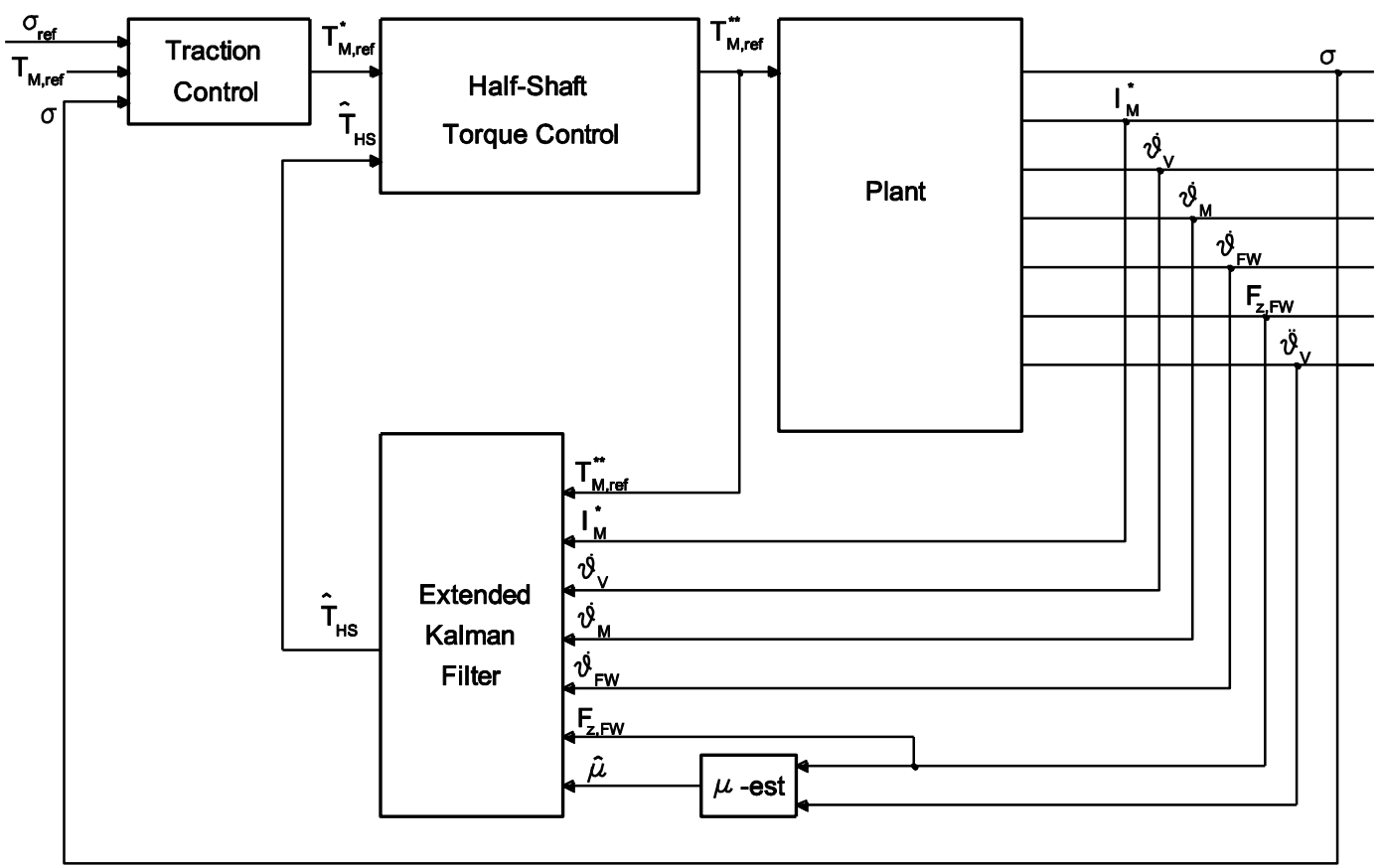

Figure 5 - Block diagram of the TC based on direct slip control as the outer control loop and the feedback controller for the compensation of half-shaft torque dynamics as the inner control loop, including the schematic detailing the input and output signals of the extended Kalman filter for half-shaft torque estimation 
A PID controller has been implemented for the feedback control of half-shaft torque as the inner control loop, according to the linearized block diagram of the system of Figure 6. The gains have been designed for the achievement of about $7 \mathrm{~dB}$ of gain margin and $60^{\circ}$ of phase margin, at a vehicle velocity of $50 \mathrm{kph}$.

As half-shaft torque cannot be directly measured on the plant, the system requires the implementation of an extended Kalman filter (Figure 5), for the estimation of the halfshaft torque level. The extended Kalman filter is based on the non-linear electric powertrain model presented in section 2 , with the exclusion of tyre relaxation length and the equations of the longitudinal vehicle dynamics. Appendix $\mathrm{C}$ presents the structure and the details of the formulation of the extended Kalman filter adopted in this contribution. The measured values of the angular velocities of the motor and the wheel and the measurement of the motor torque have been provided through sensor simulation and were pre-conditioned with properly tuned low-pass filters. The selection of the noise level for the measurements has been carried out consistently with the experimental values reported in [12]. This Kalman filter can also provide a reliable estimation of tyre longitudinal force, being characterised by a non-linear tyre model. An alternative implementation of a similar Kalman filter is presented in [23], where the filter is simplified from the viewpoint of the estimation of tyre force, but includes, within its non-linear model, the simulation of transmission plays, which can provoke significant 
driveline oscillations. The best option for the detailed implementation of the Kalman filter will be experimentally verified by the authors during the vehicle testing activity which is going to be implemented in future.

A comprehensive set of simulations has been carried out in order to check the robustness of the extended Kalman filter estimation against the variation of tyre-road friction coefficient, and against the variation of tyre parameters. In particular, for the specific case study, the filter estimation is not significantly affected even by an incorrect estimation of tyre friction coefficient, when the slip ratio is not close to the value corresponding to the peak longitudinal force. Therefore, within the implementation, the extended Kalman filter is fed with a fairly crudely estimated value of the actual tyre friction utilisation, based on the methodology presented in [27].

The new feedback controller is useful during normal driving conditions for improving vehicle drivability, and during $\mathrm{TC}$ or ABS actuation for improving wheel dynamics. If we ignore the dynamics induced by the presence of the Kalman filter on the feedback loop, the loop gain transfer function for the system including the new control loop is:

$$
\begin{aligned}
G_{L G}(s) & =G_{P L A N T, \sigma} K_{H S, C L}(s) K_{P I D, T C}(s) \\
& =G_{P L A N T, \sigma} \frac{\left[1+K_{P I D, H S}(s)\right]}{\left[1+i_{g}^{*} K_{P I D, H S}(s) G_{P L A N T, H S}(s)\right]} K_{P I D, T C}(s)
\end{aligned}
$$

At the moment, within this research focused on the analysis of the in-board powertrain dynamics, the traction control system does not include a robust adjustment of $\sigma_{\text {ref }}$ as a function of the estimated tyre characteristics. As the focus of this article is on the effect 
of the half-shaft on the dynamics of the individual wheel powertrain, the traction controllers in Figures 4 and 6 have been implemented as basic proportional controllers. The design of the gains for the TC systems has been based on the analysis of the gain margin and system stability on the Bode diagrams of the loop gain transfer functions. Typical desired values of the gain margin are between 3 and $10 \mathrm{~dB}$.

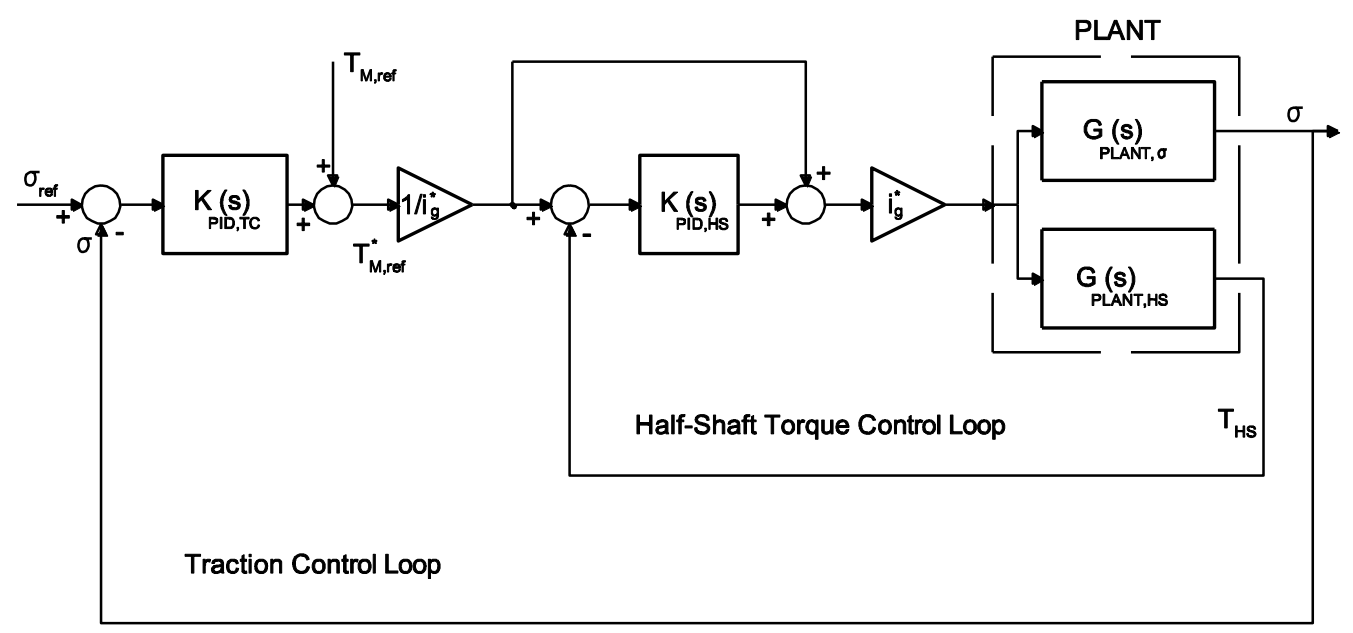

Figure 6 - Block diagram of the linearized TC (used for control system design) based on direct slip control as the outer loop and the feedback controller for the compensation of half-shaft torque dynamics as the inner loop

Figures 7 and 8 compare the performance of the traction control systems of Figures 4 and 6, from the viewpoint of the Bode plots of their loop gain (a) and closed-loop (b) transfer functions. The results have been obtained through the linearization of the model 
in an operating condition close to the peak point of the longitudinal force characteristic of the tyre (precisely at a slip ratio with an offset of 0.01 to the left of the peak slip ratio), at a vehicle velocity of $50 \mathrm{kph}$. The adoption of the half-shaft torque control inner loop provides a significant enhancement of system stability. This allows the selection of higher values of the proportional gain of the $\mathrm{TC}$, resulting in a quicker dynamic response of the controller, for the same values of gain margin, which are compared in Table 1 for different tunings of the proportional gain of the TC. Table 1 also shows a significant increase of the gain margin as a function of vehicle velocity, which implies the requirement for a gain scheduling of the controller. Due to the high non-linearity of the system, the fine tuning of the controller requires simulations in the time domain, which are presented in section 4 . Figures 7(b), 8(b) and 9 compare the closed-loop performance of the control systems of Figures 4 and 6 in the frequency domain. In particular, with the system including the feedback controller on half-shaft torque, it is possible to achieve an acceptable tracking capability (-3.5 dB of closed-loop response) up to a frequency of about $47 \mathrm{~Hz}$, well beyond the expected frequency range for TC and ABS. Additional benefits should be achievable by adopting more advanced controllers for the TC function, such as compensators and linear quadratic regulators, which will be the object of future research. 

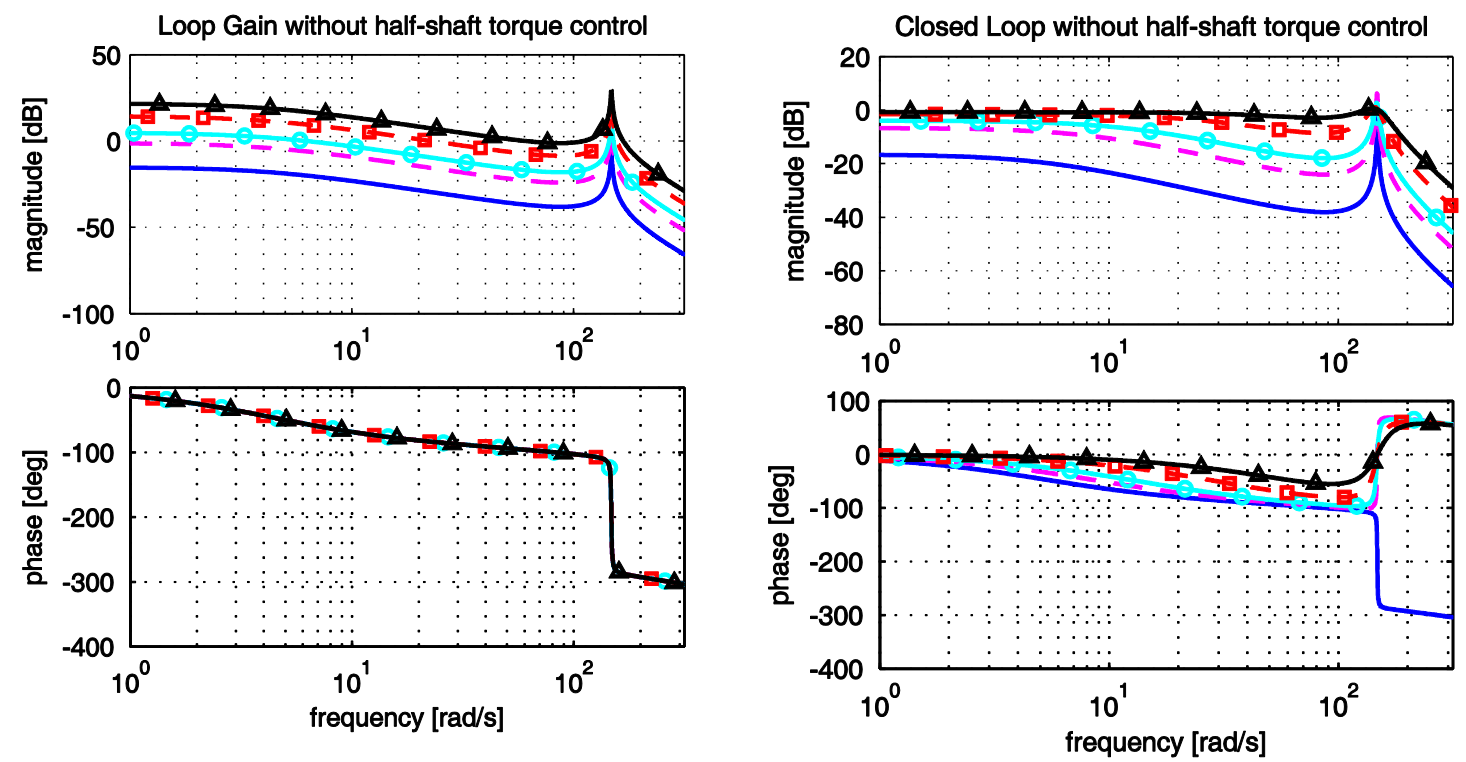

(a)

(b)

Figure 7 - Bode plots of the (a) loop gain transfer function and the (b) closed-loop transfer function of the vehicle including traction control and excluding the half-shaft torque control. The frequency response plots are shown for different values of the proportional gain of the traction control: (continuous) $10 \mathrm{Nm}$, (dashed) $50 \mathrm{Nm}$, (o) 100 Nm, ( $\square) 300 \mathrm{Nm},(\boldsymbol{\Delta}) 700 \mathrm{Nm}$ 


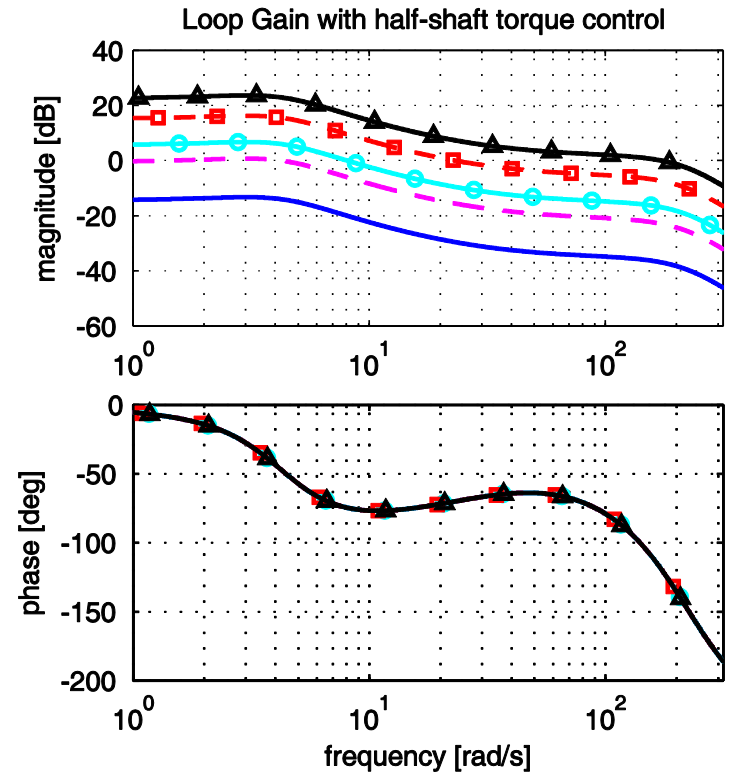

(a)

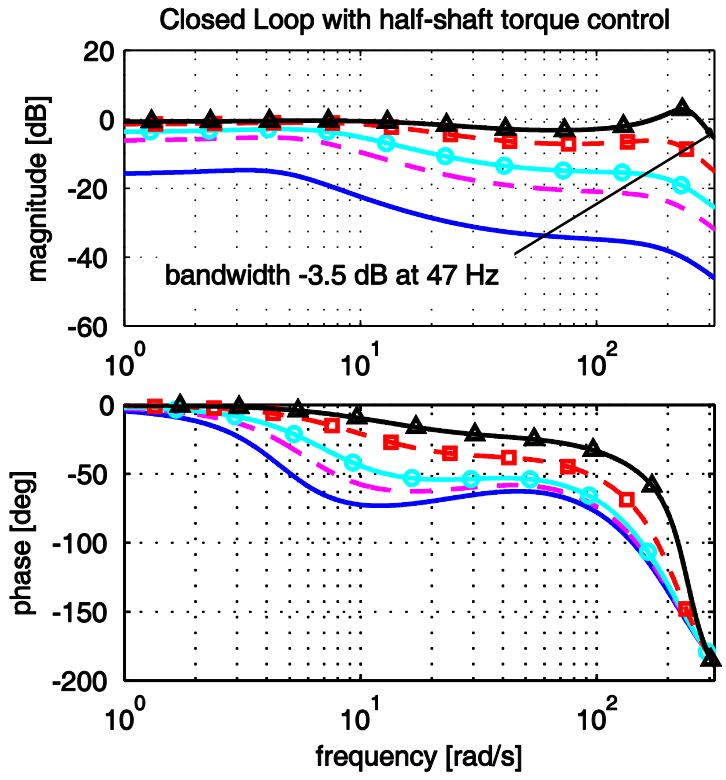

(b)

Figure 8 - Bode plots of the (a) loop gain transfer function and the (b) closed-loop transfer function of the vehicle including traction control and the half-shaft torque control. The frequency response plots are shown for different values of the proportional gain of the traction controller: : (continuous) $10 \mathrm{Nm}$, (dashed) $50 \mathrm{Nm}$, (o) $100 \mathrm{Nm},(\square)$ $300 \mathrm{Nm},(\mathbf{\Delta}) 700 \mathrm{Nm}$

\begin{tabular}{|c|c|c|c|c|c|c|}
\hline & $\begin{array}{l}\mathrm{P} \text { Gain } \\
{[\mathrm{Nm}]}\end{array}$ & 10 & 50 & 100 & 300 & 700 \\
\hline \multirow{3}{*}{$\begin{array}{c}\text { Without half-shaft } \\
\text { torque control }\end{array}$} & $20 \mathrm{kph}$ & -6.34 & $\overline{-20.3}$ & $\overline{-26.3}$ & $\overline{-35.9}$ & $\overline{-43.2}$ \\
\hline & $50 \mathrm{kph}$ & 7.82 & -2.16 & -12.2 & -21.7 & -29.1 \\
\hline & $90 \mathrm{kph}$ & 15.2 & 1.26 & -4.76 & -13.3 & -21.6 \\
\hline \multirow{3}{*}{ With half-shaft torque } & $20 \mathrm{kph}$ & 36.6 & 22.7 & 16.6 & 7.1 & -0.27 \\
\hline & $50 \mathrm{kph}$ & 44.6 & 30.6 & 24.6 & 15.1 & 7.7 \\
\hline & $90 \mathrm{kph}$ & 49.8 & 35.8 & 29.8 & 2.2 & 12.9 \\
\hline
\end{tabular}

Table 1 - Gain margin values (in $\mathrm{dB}$ ) for different tunings of the 
proportional gain ( $\mathrm{P}$ Gain) of the traction control system

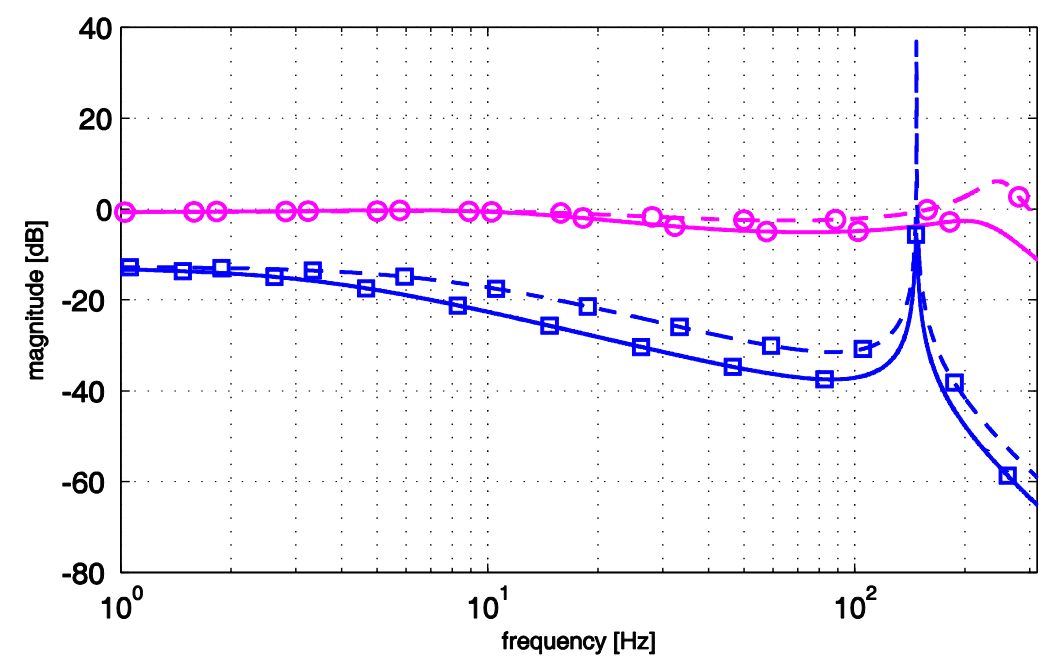

Figure 9 - Bode magnitude plot of the closed-loop transfer function of the system with traction control, excluding inner loop (marked with $\square$ ) and including inner loop (marked with o), at two different values of vehicle speed: $40 \mathrm{kph}$ (dashed line), $80 \mathrm{kph}$ (continuous line). The proportional gain of the traction control is equal to $17 \mathrm{Nm}$ in the system without the half-shaft torque control loop and it is $700 \mathrm{Nm}$ in the system with inner loop

Figure 10 is the root locus plot for the overall closed-loop system, excluding (Figure 10(a)) and including (Figure 10(b)) the half-shaft torque control system. The adoption of the novel half-shaft torque control system cancels the poles near the imaginary axis and moves the part of the root locus which progresses towards the right-hand plane 
(RHP) zeros (not pictured) further to the left. This significantly contributes to system stability, allowing the adoption of higher values of the proportional gain of the traction control system.

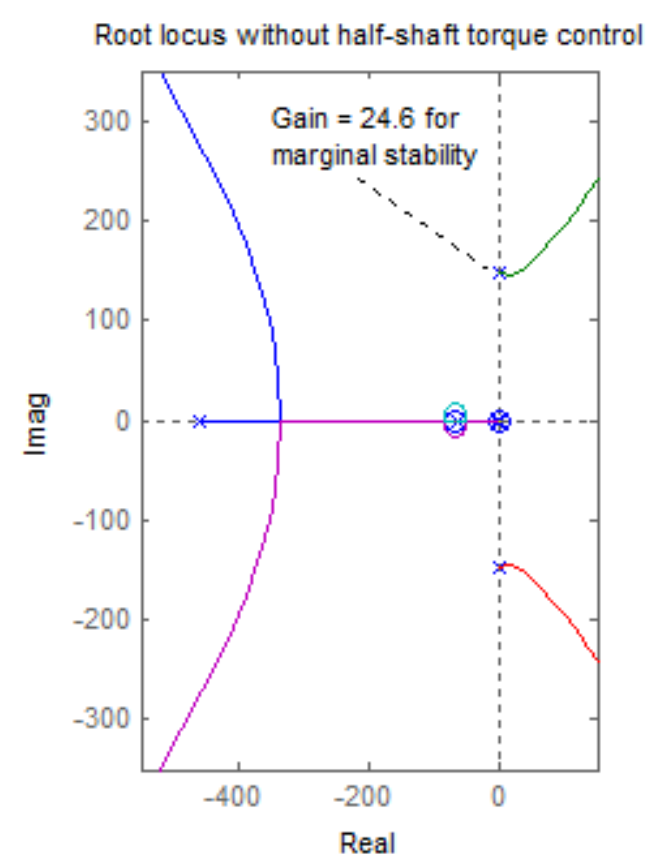

(a)

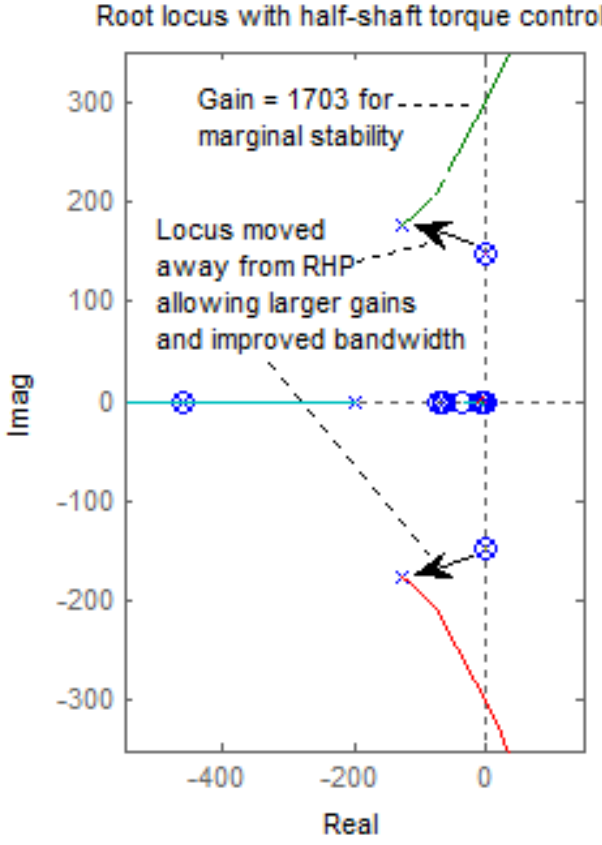

(b)

Figure 10 - Root locus analysis excluding and including half-shaft torque control at 50

$\mathrm{kph}$

\section{Results in the Time Domain}

The half-shaft torque inner control loop presented in section 3 is a useful method for modifying the loop gain frequency response such that TC/ABS slip (or anti-jerk) control design is much simpler and provides higher performance. 
Figure 11 demonstrates the functionality of the novel controller through simulation in the time domain. The electric motor torque (and hence the reference wheel torque) is ramped up to a desired steady-state level, and then a sinusoidal oscillation at a frequency of $9 \mathrm{~Hz}$ is superimposed. In Figure 11(a), the vehicle equipped with the control system can follow the reference, whilst the vehicle without the feedback control system on half-shaft torque suffers from a mean level offset, a phase lag, and a significant amplitude error in the oscillations.

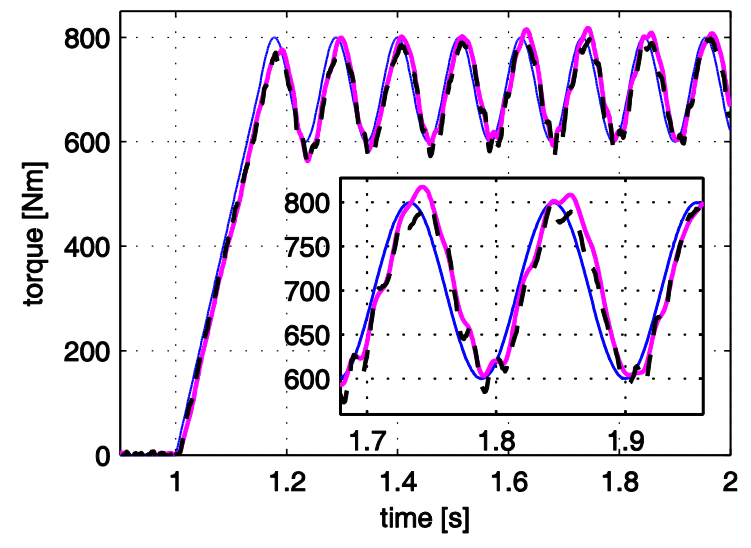

(a)

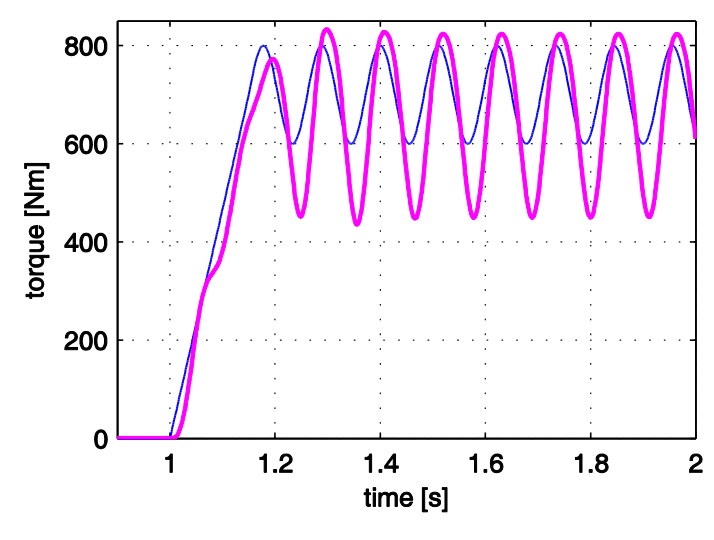

(b)

Figure 11 - Half-shaft reference torque (thin continuous line), actual half-shaft torque (thick continuous line) and Kalman filter estimation of half-shaft torque (dashed line) with half-shaft torque control (a) and with no control (b). The electric motor drive reference torque (whilst in the figure half-shaft torques are plotted) is a step of $70 \mathrm{Nm}$ plus a sinusoidal oscillation with an amplitude of $10 \mathrm{Nm}$ and a frequency of $9 \mathrm{~Hz}$.

Vehicle initial velocity is $50 \mathrm{kph}$ 
Simulations of tip-in tests (Figure 12) with the non-linear model show the typical oscillations of the vehicle acceleration profile induced by the torsional dynamics of the electric powertrains. The vehicle equipped with the feedback half-shaft torque controller is characterised by an appreciably smoother acceleration profile, with attenuated oscillations in comparison with the vehicle without the novel control system, and so the controller can be considered as an indirect anti-jerk controller.

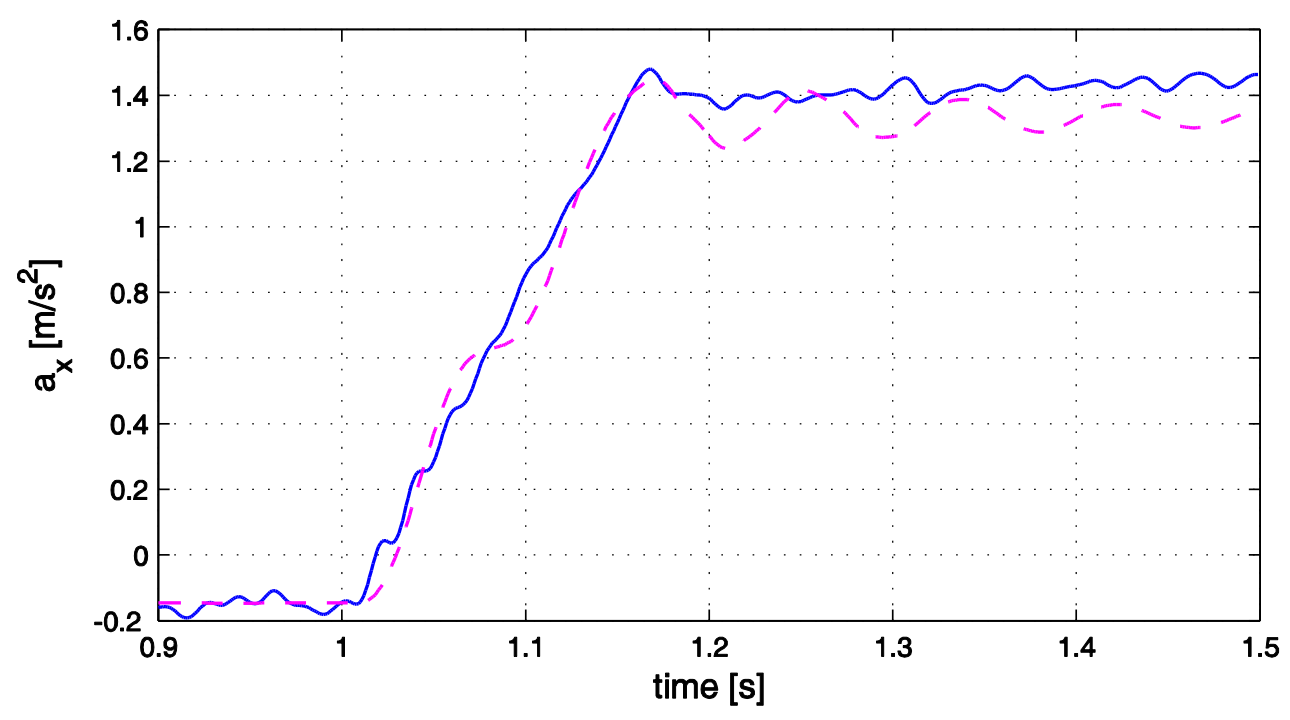

Figure 12 - Vehicle longitudinal acceleration profile during a tip-in manoeuvre with half-shaft torque control (continuous line) and without half-shaft torque control (dashed line). Final torque demand of $75 \mathrm{Nm}$ per electric motor starting from zero. Initial vehicle speed of $20 \mathrm{kph}$ 
Finally, Figure 13 is the comparison of the performance of the passive vehicle, the vehicle equipped with the TC of Figure 4 (according to two different tunings) and the vehicle equipped with the TC and the half-shaft torque control system of Figure 6, during a tip-in test from an initial speed of $50 \mathrm{kph}$. The wheel torque level during the first part of the tip-in manoeuvre is beyond the friction limit of the tyres, which implies significant wheel spinning for both the passive vehicle and the vehicle with TC only (proportional control). The TC without half-shaft torque control requires a significantly low value of the proportional gain of the controller for keeping system stability, as discussed in section 3. The stand-alone TC based tuned according to the system frequency response characteristics was unable to achieve the desired performance level with a proportional gain only. Therefore, a PID control system has also been implemented replacing the TC gain controller (still without the inner half-shaft torque control loop) in order to reduce the slip ratio especially during the first part of the wheel spinning phase.

In frequency domain terms, the PID controller can be utilised as a band-stop compensator to reduce the loop gain around the first resonant peak in order to improve the gain margin. In any case, even this TC configuration achieves a more irregular slip control dynamics in comparison with the system including the half-shaft torque inner control loop. The vehicle equipped with the novel controller and a basic proportional 
TC is characterised by the absence of any significant wheel spinning (maximum slip ratio of about 0.16 ) and a higher velocity profile than the other three vehicles.

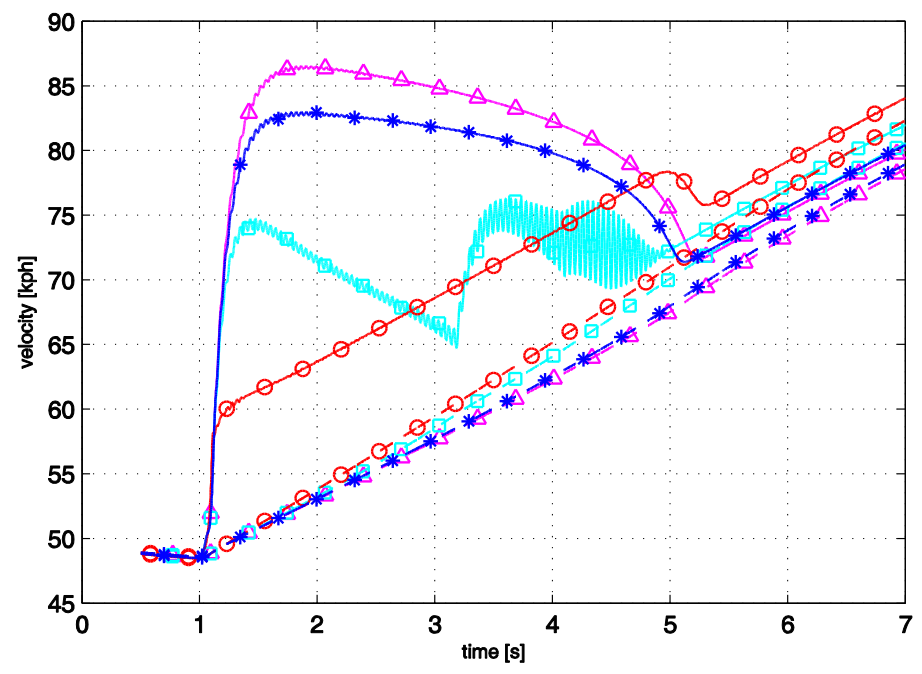

Figure 13 - Wheel (continuous line) and vehicle velocities (dashed line) during a tip-in manoeuvre. Vehicle without control system $(\boldsymbol{\Delta})$; vehicle with traction control based on a proportional gain $(*)$; vehicle with traction control based on a PID controller $(\square)$; vehicle with traction control based on a proportional gain and the novel half-shaft torque control (o)

The main performance metrics relating to the manoeuvre of Figure 13 are reported in Table 2. In particular, the novel controller proposed in this contribution allows the achievement of an average value of slip ratio very close to the reference, with a 
reduction of the peak values of the longitudinal slip ratio by a percentage between $85 \%$ and $116 \%$ in comparison with the vehicles equipped with traction control systems without the half-shaft torque feedback loop.

\begin{tabular}{|c|c|c|c|c|}
\hline & No control & $\begin{array}{l}\text { Proportional } \\
\text { gain traction } \\
\text { control }\end{array}$ & $\begin{array}{l}\text { PID traction } \\
\text { control }\end{array}$ & $\begin{array}{l}\text { Proportional } \\
\text { gain traction } \\
\text { control with } \\
\text { half-Shaft } \\
\text { torque } \\
\text { control }\end{array}$ \\
\hline $\begin{array}{c}\text { Average } \\
\text { acceleration }\end{array}$ & $1.36 \mathrm{~m} / \mathrm{s}^{2}$ & $1.39 \mathrm{~m} / \mathrm{s}^{2}$ & $1.51 \mathrm{~m} / \mathrm{s}^{2}$ & $1.58 \mathrm{~m} / \mathrm{s}^{2}$ \\
\hline $\begin{array}{l}\text { Average slip } \\
\text { ratio }\end{array}$ & $0.262(+113 \%)$ & $0.239(+94 \%)$ & $0.152(+24 \%)$ & 0.123 \\
\hline Peak slip ratio & $0.403(+129 \%)$ & $0.38(+116 \%)$ & $0.325(+85 \%)$ & 0.176 \\
\hline
\end{tabular}

Table 2 - Performance metrics of the different traction control solutions presented in the paper, during the same manoeuvre as in Figure 13. The percentage variations are referred to the proportional traction control system including half-shaft torque control (configuration in the last column on the left in the table)

\section{Conclusion}

The article has demonstrated the potential effects induced by the torsional dynamics of the half-shafts on the response of individual wheel in-board powertrains. In particular, the first natural frequency of the system, due to the torsional stiffness of the half-shaft, the mass moments of inertia of the powertrain components and the tyre characteristics at 
the operating point, is responsible for a significant deterioration of the system response in terms of wheel torque. The in-board powertrain dynamics have been compensated through a feedback controller, based on the half-shaft torque estimation using an extended Kalman filter. The performance of a case study traction control system is significantly enhanced by the adoption of the designed control system, notably achieving a tracking bandwidth up to $47 \mathrm{~Hz}$ at $-3.5 \mathrm{~dB}$.

Future work will consider incorporating this methodology into a general four-wheeldrive electric vehicle dynamics controller as part of the European $7^{\text {th }}$ Framework EVECTOORC research activity.

\section{Acknowledgements}

The authors wish to thank John De Clercq and Kevin Verhaege of Inverto NV, Miguel Dhaens and Dirk Steenbeke of Flanders' Drive and Nigel Clarke of Jaguar Land Rover for supplying the data for the specific vehicle application and for the overall support to the research project. The Engineering Faculty of Taranto of the Technical University of Bari has financially supported one of the authors (Francesco Bottiglione) using funds of the Provincia di Taranto for the support of the Faculty's teaching and scientific activities. 


\section{References}

1. Ehsani, M., Gao, Y., Emadi, A., Modern Electric, Hybrid Electric, and Fuel Cell Vehicles, $2^{\text {nd }}$ Edition, Routledge, 2009.

2. Husani, I., Electric and Hybrid Vehicles, CRC Press, 2003.

3. Miller, J. M., Propulsion Systems for Hybrid Vehicles, Ed. IEEE, 2004.

4. Ren, Q., Crolla, D.A., Morris, A., Effect of Transmission Design on Electric Vehicle (EV) Performance, IEEE Vehicle Power and Propulsion Conference, Dearborn (MI), USA, 7-11 September 2009.

5. Jacobsen, B., Potential of electric wheel motors as new chassis actuators for vehicle manoeuvring, Proceedings of the Institution of Mechanical Engineers, Part D: Journal of Automobile Engineering, Vol. 216,8, pp. 631-640, August 2002.

6. Geng, C., Mostefai, L., Denai, M., Hori, Y., Direct Yaw Moment Control of an InWheel-Motored Electric Vehicle Based on Body Slip Angle Fuzzy Observer, IEEE Transactions on Industrial Electronics, Vol. 56, No. 5, pp.1411-1419, May 2009.

7. Fujimoto, H., Fuji, K., Takahashi, N., Traction and Yaw-rate Control of Electric Vehicle with Slip-ratio and Cornering Stiffness Estimation, Proceedings of the 2007 American Control Conference, New York, July 11-13, 2007.

8. Sakai, S., Sado, H., Hori, Y., Motion Control in an Electric Vehicle with Four Independently Driven In-Wheel Motors, IEEE/ASME Transactions on Mechatronics, Vol. 4, No. 1, pp. 9-16, March 1999. 
9. Fuhrer, J., Schmitt, G., Continental Teves AG \& Co. oHG, Coordination Method for a Regenerative and Anti-Skid Braking System, US Patent 7,152,934, 2006.

10. Crombez, D.S., Ford Global Technologies LLC, Combined Regenerative and Friction Braking System for a Vehicle, US Patent 6,687,593, 2004.

11. Kidston, K.S., General Motors Corporation, Electric Vehicle with Regenerative and Anti-lock Braking, US Patent 5,615,933, 1997.

12. Johansen, T.A., Petersen, I., Kalkkuhl, J., Ludemann, J., Gain-Scheduled Wheel Slip Control in Automotive Brake Systems, IEEE Transactions on Control Systems Technology, Vol. 11, No. 6, pp. 799-811, November 2003.

13. Lv, H., Jia, Y., Du, J., Du, Q., ABS Composite Control Based on Optimal Slip Ratio, 2007 American Control Conference, New York, USA, July 11-13, 2007.

14. Drakunov, S., Ozguner, U., Dix, P., B. Ashrafi, ABS Control Using Optimum Search via Sliding Modes, IEEE Transactions on Control Systems Technology, Vol. 3, pp. 79-85, March 1995.

15. Chin, Y.K., Lin, W.C., Sidlosky, D.M., Sparschu, M.S., Sliding-Mode ABS Wheel-Slip Control, American Control Conference, Chicago, USA, June 1992.

16. Harifi, A., Aghagolzadeh, A., Alizadeh, G., Sadeghi, M., Designing a Sliding Mode Controller for Slip Control of Antilock Brake Systems, Transportation Research Part C, pp. 731-741, 2008. 
17. Choi, S.B., Anti-lock Brake System With Continuous Wheel Slip Control to Maximize the Braking Performance and the Ride Quality, IEEE Transactions on Control Systems Technology, Vol. 16, pp. 996-1003, September 2008.

18. Klein, H.C., Anti-lock Brake System for Passenger Cars - State of the Art 1985, SAE paper 865139, 1 February 1987.

19. Anderson, H. Unsprung Mass with in-wheel Motors - Myths and Realities, Proceedings of the AVEC 2010: $10^{\text {th }}$ International Symposium on Advanced Vehicle Control, 22-25 August, Loughborough.

20. Vos, R., Besselink, I.J.M., Nijmejier, H., Influence of in-wheel motors on the ride comfort of electric vehicles, Proceedings of the AVEC 2010: 10 ${ }^{\text {th }}$ International Symposium on Advanced Vehicle Control, 22-25 August, Loughborough.

21. Sorniotti, A., Driveline Modeling, Experimental Validation and Evaluation of the Influence of the Different Parameters on the Overall System Dynamics, SAE 2008 World Congress, 14 April 2008, SAE paper 2008-01-0632.

22. Grewal, S.M., Andrews, A.P., Kalman Filtering: Theory and Practice using MATLAB, $2^{\text {nd }}$ Edition, John Wiley \& Sons, 2001.

23. Amann, N., Bocker, J., Penner, F., Active Damping of Drive Train Oscillations for an Electrically Driven Vehicle, IEEE/ASME Transactions on Mechatronics, Vol. 9, No. 4, pp. 697-700, December 2004. 
24. Pacejka, H.B., Tyre and Vehicle Dynamics, $2^{\text {nd }}$ Edition, Ed. ButterworthHeinemann, 2005.

25. Murata, S., Innovation by In-Wheel-Motor Drive Unit, Keynote Presentation, Proceedings of the AVEC 2010: $10^{\text {th }}$ International Symposium on Advanced Vehicle Control, 22-25 August, Loughborough.

26. Cherian, V., Jalili, N., Agylon, Modelling, simulation, and experimental verification of the kinematics and dynamics of a double wishbone suspension configuration, Proceedings of the Institution of Mechanical Engineers, Part D: Journal of Automobile Engineering, Vol. 223, pp. 1239-1262, October 2009.

27. Hori, Y., Toyoda, Y., Tsuruoka, Y., Traction Control of Electric Vehicles: Basic Experimental Results Using the Test EV 'UOT Electric March', IEEE Transactions on Industry Applications, Vol. 34, No. 5, pp. 1131-1138, September/October 1998. 
Appendix A - Matrices of the State-Space Formulation of the Linearised Vehicle

\section{Model}

Each element of the matrices of the first equation of (2.9) is here defined.

$\underline{\text { State vector }}$

$$
X^{T}=\left[\dot{\theta}_{M}, \dot{\theta}_{F W}, \dot{\theta}_{V}, \theta_{M}, \theta_{F W}, T_{M}, T_{d}\right]
$$

$\underline{\text { State matrix }}$

$$
A=\left[\begin{array}{ccccccc}
a_{1,1} & a_{1,2} & 0 & a_{1,4} & a_{1,5} & a_{1,6} & 0 \\
a_{2,1} & a_{2,2} & 0 & a_{2,4} & a_{2,5} & 0 & a_{2,7} \\
0 & 0 & a_{3,3} & 0 & 0 & 0 & a_{3,7} \\
1 & 0 & 0 & 0 & 0 & 0 & 0 \\
0 & 1 & 0 & 0 & 0 & 0 & 0 \\
0 & 0 & 0 & 0 & 0 & a_{6.6} & 0 \\
0 & a_{7,2} & a_{7,3} & 0 & 0 & 0 & a_{7,7}
\end{array}\right]
$$

where the non-null terms are:

$$
\begin{aligned}
& a_{1,1}=-\frac{i_{g}^{* 2} \beta_{H S}}{\eta^{*} J_{M}^{*}} \quad a_{1,2}=\frac{i_{g}^{*} \beta_{H S}}{\eta^{*} J_{M}^{*}} \quad a_{1,4}=-\frac{i_{g}^{* 2} k_{H S}}{\eta^{*} J_{M}^{*}} \quad a_{1,5}=\frac{i_{g}^{*} k_{H S}}{\eta^{*} J_{M}^{*}} \quad a_{1,6}=\frac{1}{J_{M}^{*}} \\
& a_{2,1}=-\frac{\eta_{j 2} \beta_{H S} i_{g}^{*}}{J_{F W}^{*}} \quad a_{2,2}=-\frac{\eta_{j 2} \beta_{H S}+\left(f_{1}+2 f_{2} R_{W} \dot{\theta}_{F W, 0}\right) R_{W}^{2} F_{z, F W, 0}}{J_{F W}^{*}} \\
& a_{2,4}=\frac{\eta_{j 2} k_{H S} i_{g}^{*}}{J_{F W}^{*}} \quad a_{2,5}=-\frac{\eta_{j 2} k_{H S}}{J_{F W}^{*}} \quad a_{2,7}=-\frac{1}{J_{F W}^{*}} \\
& a_{3,3}=-\frac{2\left(f_{1}+2 f_{2} R_{W} \dot{\theta}_{V, 0}\right) R_{W}^{2} F_{z, R W}+\rho C_{d} S R_{W}^{3} \dot{\theta}_{V, 0}}{J_{V}^{*}} \quad a_{3,7}=\frac{2}{J_{V}^{*}}
\end{aligned}
$$




$$
\begin{aligned}
& a_{6,6}=-\frac{1}{\tau_{M}} \\
& a_{7,2}=\frac{\dot{\theta}_{V, 0} \beta_{F W}}{\dot{\theta}_{F W, 0} \tau_{W}} \quad a_{7,3}=-\frac{\beta_{F W}}{\tau_{W}} \quad a_{7,7}=-\frac{1}{\tau_{W}} \\
& J_{M}^{*}=\left(J_{M}+J_{1}\right)+\frac{i_{g 1}^{2}}{\eta_{1}} J_{2}+\frac{\left(i_{g 1} i_{g 2}\right)^{2}}{\eta_{1} \eta_{2}} J_{3}+\frac{\left(i_{g 1} i_{g 2} i_{g 3}\right)^{2}}{\eta_{1} \eta_{2} \eta_{3}}\left(J_{4}+\frac{1}{2} \frac{J_{H S}}{\eta_{j 1}}\right) \\
& J_{F W}^{*}=J_{F W}+\eta_{j 2} \frac{J_{H S}}{2} \quad J_{V}^{*}=2 J_{R W}+m R_{W}^{2} \quad i_{g}^{*}=i_{g 1} i_{g 2} i_{g 3} \quad \eta^{*}=\eta_{1} \eta_{2} \eta_{3} \eta_{j 1}
\end{aligned}
$$

\section{Input vector}

$$
\begin{aligned}
U^{T}=\left[T_{r e f},-f_{0} R_{W} F_{z, F W, 0}, f_{2} R_{W}^{3} \dot{\theta}_{F W, 0}^{2} F_{z, F W, 0},\right. & -f_{0} R_{W} F_{z, R W, 0}, f_{2} R_{W}^{3} \dot{\theta}_{V, 0}^{2} F_{z, R W, 0}, \\
& \left.\frac{1}{2} \rho C_{d} S R_{W}^{3} \dot{\theta}_{V, 0}^{2}, \beta_{F W}\left(\dot{\theta}_{F W, 0}-\dot{\theta}_{V, 0}\right)\right]
\end{aligned}
$$

$\underline{\text { Input matrix }}$

$$
B=\left[\begin{array}{ccccccc}
0 & 0 & 0 & 0 & 0 & 0 & 0 \\
0 & \frac{1}{J_{F W}^{*}} & \frac{1}{J_{F W}^{*}} & 0 & 0 & 0 & 0 \\
0 & 0 & 0 & \frac{2}{J_{V}^{*}} & \frac{2}{J_{V}^{*}} & \frac{1}{J_{V}^{*}} & 0 \\
0 & 0 & 0 & 0 & 0 & 0 & 0 \\
0 & 0 & 0 & 0 & 0 & 0 & 0 \\
\frac{1}{\tau_{M}} & 0 & 0 & 0 & 0 & 0 & 0 \\
0 & 0 & 0 & 0 & 0 & 0 & \frac{\dot{\theta}_{W, 0} R_{W}}{L_{t y r e}}
\end{array}\right]
$$


Appendix B - List of the Main Vehicle Parameters

\begin{tabular}{|c|c|}
\hline Symbol & Value \\
\hline \multicolumn{2}{|l|}{ Vehicle parameters } \\
\hline$M$ & $2500 \mathrm{~kg}$ \\
\hline$L$ & $2.660 \mathrm{~m}$ \\
\hline$b$ & $1.350 \mathrm{~m}$ \\
\hline$h_{C G}$ & $0.65 \mathrm{~m}$ \\
\hline$C_{d}$ & 0.39 \\
\hline$S$ & $2.76 \mathrm{~m}^{2}$ \\
\hline \multicolumn{2}{|l|}{ Wheel parameters } \\
\hline$R_{W}$ & $370 \mathrm{~mm}$ \\
\hline$J_{F W}=J_{R W}$ & $0.9 \mathrm{~kg} \mathrm{~m} \mathrm{~m}^{2}$ \\
\hline \multicolumn{2}{|l|}{ Half-shaft } \\
\hline \multicolumn{2}{|l|}{ parameters } \\
\hline \multicolumn{2}{|l|}{ Material } \\
\hline \multicolumn{2}{|l|}{$d_{H S}$} \\
\hline \multicolumn{2}{|r|}{$506 \mathrm{~mm}$} \\
\hline \multicolumn{2}{|l|}{ Gearbox parameters } \\
\hline \multicolumn{2}{|l|}{ Motor parameters } \\
\hline$T_{M, \max }$ & $200 \mathrm{Nm}$ \\
\hline$P_{M, \max }$ & $80 \mathrm{~kW}$ \\
\hline$J_{M}$ & $0.016 \mathrm{~kg} \mathrm{~m} \mathrm{~m}^{2}$ \\
\hline
\end{tabular}

Table B.1 - Main vehicle parameters

Appendix C - Formulation of the extended Kalman filter for half-shaft torque estimation

The process is governed by the following non-linear stochastic difference equation $f$ : 
$X_{k}=f\left(X_{k-1}, U_{k-1}, W_{k-1}\right)$

where $W$ is the process noise vector. $h$ is the non-linear measurement equation (the vector of the measured variables is $Z$ ) and $V$ is the measurement noise vector:

$Z_{k}=h\left(X_{k}, V_{k}\right)$

The extended Kalman filter has been implemented according to the general algorithm detailed in the following steps 1)-6):

1) Provide an initial estimate for $X_{k-1}$ and $P_{k-1}$, where $P$ is the error covariance matrix.

2) Project the state ahead:

$\hat{X}_{k}^{(-)}=f\left(\hat{X}_{k-1}, U_{k-1}, 0\right)$

where $\hat{X}_{k}{ }^{(-)}$is the a-priori estimate of the state at step $k, \hat{X}_{k-1}$ is the a-posteriori estimate of the state at step $k-1, U_{k-1}$ is the input vector at step $k-1$ and 0 is the process error estimate at step $k-1$.

3) Project the error covariance ahead:

$P_{k}^{(-)}=A^{K F}{ }_{k} P_{k-1} A^{K F}{ }_{k}{ }^{T}+W^{K F} Q_{k-1} W^{K F}{ }_{k}^{T}$

where $A^{K F}$ is the Jacobian matrix of the partial derivatives of $f$ with respect to $X, W^{K F}$ is the Jacobian matrix of $f$ with respect to $W$ and $Q$ is the process noise covariance.

4) Compute the Kalman gain: 
$K_{k}=P_{k}{ }^{-} H_{k}{ }^{T}\left(H_{k} P_{k}{ }^{-} H_{k}{ }^{T}+V_{k}^{K F} R_{k} V_{k}^{K F}\right)^{T}$

where $H$ is the Jacobian matrix of $h$ with respect to $X, V^{K F}$ is the Jacobian matrix of $h$ with respect to $V$ and $R$ is the measurement noise covariance.

5) Update the estimate with measurement $Z_{k}$

$$
\hat{X}_{k}=\hat{X}_{k}{ }^{-}+K_{k}\left(Z_{k}-h\left(\hat{X}_{k}^{-}, 0\right)\right)
$$

6) Update the error covariance:

$$
P_{k}=\left(I-K_{k} H_{k}\right) P_{k}^{-}
$$

For the particular system of this contribution, the state vector at step $k$ is:

$$
X_{k}=\left\{\dot{\theta}_{M_{k}}, \dot{\theta}_{W_{k}}, \theta_{M_{k}}, \theta_{W_{k}}, T_{M_{k}}\right\}^{T}
$$

The non-linear system of difference equations $X_{k}=f\left(X_{k-1}, U_{k-1}, W_{k-1}\right)$ is the following:

$$
\begin{aligned}
\dot{\theta}_{M_{k}}=\left(1-\frac{i_{g}{ }^{* 2} \beta_{H S} \Delta t_{K F}}{\eta^{*} J_{M}{ }^{*}}\right) \dot{\theta}_{M_{k-1}}+\frac{i_{g}{ }^{*} \beta_{H S} \Delta t_{K F}}{\eta^{*} J_{M}{ }^{*}} \dot{\theta}_{W_{k-1}} \\
\quad-\frac{i_{g}{ }^{2} k_{H S} \Delta t_{K F}}{\eta^{*} J_{M}{ }^{*}} \theta_{M_{k-1}}+\frac{i_{g}{ }^{*} k_{H S} \Delta t_{K F}}{\eta^{*} J_{M}{ }^{*}} \theta_{W_{k-1}}+\frac{\Delta t_{H S}}{J_{M}{ }^{*}} T_{M} \\
+w_{1_{k-1}}
\end{aligned}
$$




$$
\begin{aligned}
& \dot{\theta}_{W_{k}}=\frac{\eta_{j 2} i_{g}^{*} \beta_{H S} \Delta t_{K F}}{J_{W}{ }^{*}} \dot{\theta}_{M k-1} \\
& +\left(1-\frac{\eta_{j 2} \beta_{H S} \Delta t_{K F}}{J_{W}{ }^{*}}-\frac{f_{1} R_{W}{ }^{2} F_{z_{W}} \Delta t_{K F}}{J_{W}{ }^{*}}\right. \\
& \left.-\frac{f_{2} R_{W}{ }^{3} F_{Z_{W}} \Delta t_{K F}}{J_{W}{ }^{*}} \dot{\theta}_{W_{k-1}}\right) \dot{\theta}_{W_{k-1}}+\frac{\eta_{j 2} i_{g}{ }^{*} k_{H S} \Delta t_{K F}}{J_{W}{ }^{*}} \theta_{M_{k-1}} \\
& -\frac{\eta_{j 2} k_{H S} \Delta t_{K F}}{J_{W}{ }^{*}} \theta_{W_{k-1}}-\frac{T_{W, \text { Pace jka }}{ }_{k-1} \Delta t_{K F}}{J_{W}{ }^{*}}-\frac{f_{0} F_{z_{W}} R_{W} \Delta t_{K F}}{J_{W}{ }^{*}} \\
& +w_{2 k-1} \\
& \theta_{M_{k}}=\dot{\theta}_{M_{k-1}} \Delta t_{K F}+\theta_{M_{k-1}}+w_{3_{k-1}} \\
& \theta_{W_{k}}=\dot{\theta}_{W_{k-1}} \Delta t_{K F}+\theta_{W_{k-1}}+w_{4_{k-1}} \\
& T_{M_{k}}=\left(1-\frac{\Delta t_{K F}}{\tau_{M}}\right) T_{M_{k-1}}+T^{* *}{ }_{M, r e f}{ }_{k-1} \frac{\Delta t_{H S}}{\tau_{M}}+w_{5_{k-1}}
\end{aligned}
$$

The measurement vector is $\tilde{Z}_{k}=\left\{\tilde{\dot{\theta}}_{M_{k}}, \tilde{\dot{\theta}}_{W_{k}}, \widetilde{T}_{M_{k}}\right\}^{T}$ and its elements at step $k$ are:

$$
\begin{aligned}
& \tilde{\theta}_{M_{k}}=\dot{\theta}_{M_{k}}+v_{1_{k}} \\
& \tilde{\dot{\theta}}_{W_{k}}=\dot{\theta}_{W_{k}}+v_{2_{k}} \\
& \tilde{T}_{M_{k}}=T_{M_{k}}+v_{3_{k}}
\end{aligned}
$$

$A^{K F}$ is the Jacobian matrix of partial derivatives of $f$ with respect to $X$ : 


$$
\begin{aligned}
& A^{K F}=\left[\begin{array}{ccccc}
a_{11}{ }^{K F} & a_{12}{ }^{K F} & a_{13}{ }^{K F} & a_{14}{ }^{K F} & a_{15}{ }^{K F} \\
a_{21}{ }^{K F} & a_{22}{ }^{K F} & a_{23}{ }^{K F} & a_{24}{ }^{K F} & 0 \\
a_{31}{ }{ } & 0 & 1 & 0 & 0 \\
0 & a_{42}{ }^{K F} & 0 & 1 & 0 \\
0 & 0 & 0 & 0 & a_{55}{ }^{K F}
\end{array}\right] \\
& a_{11}{ }^{K F}=1-\frac{i_{g}^{* 2} \beta_{H S} \Delta t_{K F}}{\eta^{*} J_{M}{ }^{*}} \\
& a_{12}{ }^{K F}=\frac{i_{g}{ }^{*} \beta_{H S} \Delta t_{K F}}{\eta^{*} J_{M}{ }^{*}} \\
& a_{13}{ }^{K F}=-\frac{i_{g}{ }^{* 2} k_{H S} \Delta t_{K F}}{\eta^{*} J_{M}{ }^{*}} \\
& a_{14}{ }^{K F}=\frac{i_{g}{ }^{*} k_{H S} \Delta t_{K F}}{\eta^{*} J_{M}{ }^{*}} \\
& a_{15}{ }^{K F}=\frac{\Delta t_{H S}}{J_{M}{ }^{*}} \\
& a_{21}{ }^{K F}=\frac{\eta_{j 2} i_{g}{ }^{*} \beta_{H S} \Delta t_{K F}}{J_{W}{ }^{*}} \\
& a_{22}{ }^{K F}=1-\frac{\eta_{j 2} \beta_{H S} \Delta t_{K F}}{J_{W}{ }^{*}}-\frac{f_{1} R_{W}{ }^{2} F_{Z_{W}} \Delta t_{K F}}{J_{W}{ }^{*}}-\frac{2 f_{2} R_{W}{ }^{3} F_{Z_{W}} \Delta t_{K F}}{J_{W}{ }^{*}} \dot{\theta}_{W}-\frac{\partial T_{W, \text { Pacejka }}}{\partial \dot{\theta}_{W}} \frac{\Delta t_{K F}}{J_{W}{ }^{*}} \\
& a_{23}{ }^{K F}=\frac{\eta_{j 2} i_{g}{ }^{*} k_{H S} \Delta t_{K F}}{J_{W}{ }^{*}} \\
& a_{24}{ }^{K F}=-\frac{\eta_{j 2} k_{H S} \Delta t_{K F}}{J_{W}{ }^{*}} \\
& a_{31}{ }^{K F}=\Delta t_{K F} \\
& a_{42}{ }^{K F}=\Delta t_{K F}
\end{aligned}
$$


$a_{55}{ }^{K F}=\left(1-\frac{\Delta t_{K F}}{\tau_{M}}\right)$

The Jacobian matrices $H, W^{K F}$ and $V^{K F}$ are identity matrices.

\section{Appendix D - List of Notations}

$A$ : state matrix (for the state-space model formulation)

$a_{i j}$ : element on the $i$-th row and $j$-th column of the state matrix

$A^{K F}$ : Jacobian matrix of the partial derivatives of $f$ with respect to $X$

$a_{i j}{ }^{K F}$ : element on the $i$-th row and $j$-th column of the matrix $A^{K F}$

$b$ : rear semi-wheelbase 
$B$ : input matrix (for the state-space model formulation)

$C$ : output matrix (for the state-space model formulation)

$C_{d}$ : aerodynamic drag coefficient

$C_{l}$ : aerodynamic lift coefficient

$C_{m}$ : aerodynamic pitch moment coefficient

$D$ : feedthrough matrix (for the state-space model formulation)

$d_{H S}:$ half-shaft diameter

$f:$ Kalman Filter non linear difference equation of system state

$f_{r}$ : tyre rolling resistance coefficient

$f_{0}$ : part of the tyre rolling resistance coefficient independent from wheel tangential velocity

$f_{1}$ : term of the tyre rolling resistance coefficient to be multiplied by wheel tangential velocity

$f_{2}$ : term of the tyre rolling resistance coefficient to be multiplied by wheel tangential velocity squared

$F_{z, W}$ : vertical force between the wheel and the road

$g$ : gravity

$G_{C L, T C, \text { conventional }}$ closed-loop transfer function $\frac{\bar{\sigma}}{\bar{\sigma}_{r e f}}(s)$ of the vehicle with traction control system based on direct slip control, without the feedback control of half-shaft torque 
$G_{L G}$ l loop gain transfer function of the system

$G_{P L A N T}:$ transfer function of the plant (the vehicle)

$G_{P L A N T, H S}$ : transfer function of the plant (the vehicle), providing half-shaft torque as output

$G_{P L A N T, \sigma}:$ transfer function of the plant (the vehicle), providing slip ratio as output

$H$ : Jacobian matrix of the function $h$ with respect to $X$

$h$ : Kalman Filter non-linear measurement equation

$h_{C G}$ : centre of gravity height

$i_{g}{ }^{*}$ : overall gear ratio of the single-speed transmission

$i_{g 1}$ : gear ratio of the first stage of the single-speed transmission

$i_{g 2}:$ gear ratio of the second stage of the single-speed transmission

$i_{g 3}:$ gear ratio of the third stage of the single-speed transmission

$J_{H S}$ : mass moment of inertia of the half-shaft

$J_{M}$ : mass moment of inertia of the electric motor

$J_{M}^{*}$ : mass moment of inertia of the electric powertrain at the motor

$J_{V}^{*}$ : equivalent mass moment of inertia of the vehicle

$J_{W}$ : mass moment of inertia of a wheel

$J_{W}^{*}$ : equivalent mass moment of inertia of a wheel

$J_{1}$ : mass moment of inertia of the transmission input shaft (Figure 1)

$J_{2}$ : mass moment of inertia of transmission shaft 2 (Figure 1) 
$J_{3}$ : mass moment of inertia of transmission shaft 3 (Figure 1)

$J_{4}$ : mass moment of inertia of the transmission output shaft (Figure 1)

$k$ : discretisation step parameter

$K$ : Kalman gain

$k_{H S}:$ torsional stiffness of the half-shaft

$K_{H S, C L}$ : closed-loop transfer function of the half-shaft torque control system

$K_{P I D, T C}:$ transfer function of the traction control system (PID controller)

$L$ : vehicle wheelbase

$l_{H S}$ : half-shaft length

$L_{\text {tyre: }}$ tyre relaxation length

$m$ : vehicle mass

$P$ : error covariance matrix

$P_{M, \text { max }}:$ maximum motor power

$Q$ : process noise covariance matrix

$R$ : measurement noise covariance

$R_{W}$ : tyre radius

$s$ : Laplace variable

$S$ : frontal area of the vehicle (for aerodynamic force and moment computation)

$T_{\text {driver }}:$ driver torque demand (for the electric motor drive) 
$T_{d, W}$ : delayed (due to tyre relaxation length effect) torque between tyre and road (with time derivative $\dot{T}_{d, F W}$ )

$T_{H S}$ : half-shaft torque

$T_{M}$ : electric motor torque (with time derivative $\dot{T}_{M}$ )

$T_{M, \max }:$ maximum electric motor torque

$T_{M, r e f}$ reference electric motor torque, according to driver input

$T_{M, r e f}^{*}:$ reference electric motor torque from the traction control (Figure 5)

$T_{M, r e f}^{* *}:$ reference electric motor torque from the half-shaft torque control (Figure 5)

$T_{W}$ : net torque transmitted by the half-shaft to the driven wheel

$T_{\text {windage }}$ : electric motor torque windage losses

$T_{W, P a c e j k a}:$ tyre torque according to the Pacejka magic formula model

$U$ : input vector (for the state-space model formulation)

$u_{W}$ : longitudinal offset (due to the rolling resistance coefficient) between tyre normal force and the centre of the contact patch

$V:$ measurement noise vector

$V^{K F}$ : Jacobian matrix of the function $h$ with respect to $V$

$W$ : process noise vector

$W^{K F}$ : Jacobian matrix of $f$ with respect to $W$

$X$ : state vector (for the state-space model formulation) 
$Y$ : output vector (for the state-space model formulation)

$Z$ : measurement vector

$\beta_{H S}$ : torsional damping coefficient of the half-shaft

$\Delta t_{K F}:$ Kalman Filter time step

$\eta^{*}:$ overall efficiency of the single-speed transmission including the constant velocity

joint

$\eta_{j l}$ : efficiency of the inner constant velocity joint

$\eta_{j 2}$ : efficiency of the outer constant velocity joint

$\eta_{1}$ : efficiency of the first stage of the single-speed transmission

$\eta_{2}$ : efficiency of the second stage of the single-speed transmission

$\eta_{3}$ : efficiency of the third stage of the single-speed transmission

$\theta_{M}, \dot{\theta}_{M}, \ddot{\theta}_{M}$ : angular displacement, velocity and acceleration of the electric motor shaft

$\dot{\theta}_{V}, \ddot{\theta}_{V}$ : angular velocity and acceleration of the equivalent inertia of the vehicle

$\theta_{W}, \dot{\theta}_{W}, \ddot{\theta}_{W}:$ angular displacement, velocity and acceleration of a driven wheel

$\rho:$ air density

$\sigma:$ tyre slip ratio

$\sigma_{P E A K}:$ tyre slip ratio at which the peak longitudinal force is achieved

$\sigma_{\text {ref: }}$ reference slip ratio

$\tau_{M}$ : electrical time constant of the electric motor drive 
$\mu$ : tyre-road friction coefficient

In the frequency domain, the parameters have the same notation as in the time domain, with a horizontal line at the top.

The subscript ' 0 ' refers to the initial condition of a state variable.

The subscripts ' ${ }_{F}$ ' and ' $\mathrm{R}$ ' refer to front and rear components of the vehicle.

The symbol “^ ' refers to the estimated variables.

The symbol "-, refers to the Laplace transform of a variable in the time domain.

The symbol “ ${ }^{\sim 2}$ refers to a measured state. 